\title{
REVIEW OF NUCLEAR THERMAL PROPULSION GROUND TEST OPTIONS David Coote ${ }^{1}$, Kevin Power $^{1}$, Harold Gerrish ${ }^{2}$, Glenn Doughty ${ }^{2}$
}

\author{
${ }^{1}$ NASA John C. Stennis Space Center, EA00/Engineering and Test Directorate, SSC, MS 39529; (228) 688-
} 1056; david.j.coote@nasa.gov, ${ }^{2}$ NASA Marshal Space Flght Center, Huntsville, AL....

\begin{abstract}
High efficiency rocket propulsion systems are essential for humanity to venture beyond the moon. Nuclear Thermal Propulsion (NTP) is a promising alternative to conventional chemical rockets with relatively high thrust and twice the efficiency of highest performing chemical propellant engines. NTP utilizes the coolant of a nuclear reactor to produce propulsive thrust. An NTP engine produces thrust by flowing hydrogen through a nuclear reactor to cool the reactor, heating the hydrogen and expelling it through a rocket nozzle. The hot gaseous hydrogen is nominally expected to be free of radioactive byproducts from the nuclear reactor; however, it has the potential to be contaminated due to off-nominal engine reactor performance.

NTP ground testing is more difficult than chemical engine testing since current environmental regulations do not allow/permit open air testing of NTP as was done in the 1960's and 1970's for the Rover/NERVA program. A new and innovative approach to rocket engine ground test is required to mitigate the unique health and safety risks associated with the potential entrainment of radioactive waste from the NTP engine reactor core into the engine exhaust.
\end{abstract}

Several studies have been conducted since the ROVER/NERVA program in the 1970's investigating NTP engine ground test options to understand the technical feasibility, identify technical challenges and associated risks and provide rough order of magnitude cost estimates for facility development and test operations. The options can be divided into two distinct schemes; (1) real-time filtering of the engine exhaust and its release to the environment or (2) capture and storage of engine exhaust for subsequent processing (reference 1, 2, 3...).

In 2011, NASA's Advanced Exploration Systems (AES) Office initiated the Nuclear Cryogenic Propulsion Stage (NCPS) Project with the goal of assessing the affordability and viability of an NCPS. Under the NCPS Project, NASA started investigating and evaluating ground test facility options that enable environmentally safe and thorough testing of NTP devices. Three options have been considered to mitigate the hazard potential of radioactive byproduct entrainment in the hydrogen flow; (1) Firing the engine exhaust into a large bore hole in alluvium soil to filter the exhaust of potential radioactive by products, (2) Completely containing the engine exhaust during engine test operations and subsequently disposed of it between engine tests, and (3) Flowing the engine exhaust through a series of aerosol and noble gas filters and venting the filtered exhaust to the atmosphere.

This paper reviews the NCPS Project's investigation of respective NTP engine test facilities, compare the options and review the current status of facility cost estimating and the NTP Project plans for 2015 in regard to the engine test facility concept trades.

Three NTP engine ground test concepts are being investigated:

NTP Engine Exhaust into an Alluvium Soil Borehole (an 8ft wide x $1200 \mathrm{ft}$ deep hole for a $25 \mathrm{klbf}$ NTP engine), where an NTP engine exhausts into a ground borehole, relying on the permeability of alluvium soil to filter the exhaust; the permeability of hydrogen through the soil and its buoyancy will allow it to rise up through the soil and allow the filtering of noble gases and radioactive particulates. The exhaust needs to be cooled to 600C before entering the borehole to avoid soil glazing. Preliminary analysis shows a small buildup of back pressure with time which depends on permeability. Noble gases entering the borehole walls can take a long 
time before reaching the surface. Other factors affecting permeability include borehole pressure, water saturation, and turbulence. Also, a possible need to pump out contaminated water collected at the bottom of the borehole. Further definition and inves

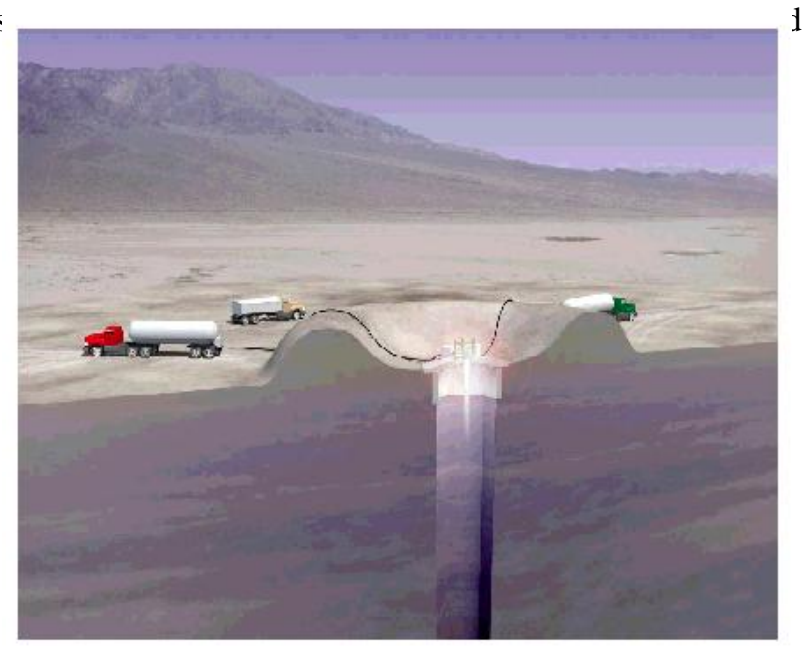

\section{Bore Hole Concept}

- Above Ground NTP Engine Exhaust Scrubber, where engine exhaust is filtered of radioactive aerosols and noble gases and directly flared to atmosphere. Concept successfully tested at the end of Rover/NERVA project at sub-scale (a 2500 lbf reactor) in Nuclear Furnace (NF-1) program (ref. xxx). The system cooled the hot hydrogen exhaust from the engine with a water spray before entering a particle filter. The exhaust then passed through a series of heat exchangers and water separators to help remove water from the exhaust and further reduce the exhaust temperatures. The exhaust was next prepared for the charcoal trap by passing through a dryer and effluent cooler to bring exhaust temperatures close to that of liquid nitrogen. The filtered hydrogen is finally passed through a flare stack and released to the air. The concept was overall successful but had multiple recommendations for improvement. This concept benefits from existing DOE and ASME standards being available for nuclear air cleaning and gaseous waste treatment. Requires acceptance of testing hazard risks (i.e., release of radioactive products to the atmosphere) to be as low as reasonably achievable (ALARA) versus zero. Further investigation is required to quantify ALARA for this concept and improve the fidelity of the cost estimate for a full scale system.

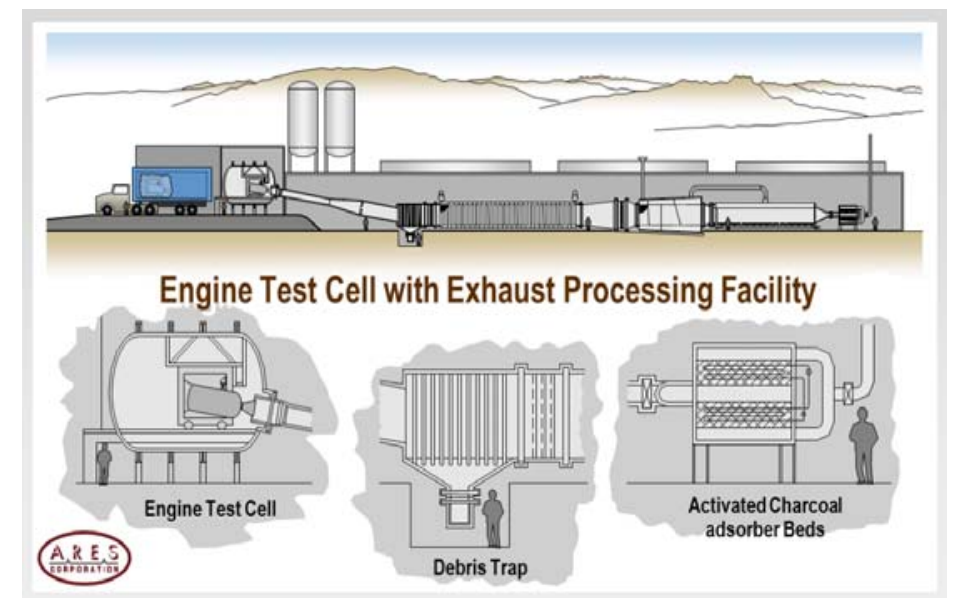

\section{Above Ground Engine Exhaust Scrubber Concept}

- An NTP Engine Exhaust Total Containment facility mitigates general misconceptions of the hazard risks of NTP engine development/qualification testing; engine exhaust is completely contained within a relatively small volume isolated from the local environment during engine test operations and subsequently released to the environment after all radioactive waste has been eliminated from it; i.e., no radioactive waste is released to the environment. The NTP engine's hydrogen exhaust is burned at high temperatures with oxygen and produces steam to be cooled, condensed, and collected for controlled processing and disposal.

Prior investigations into NTP engine exhaust processing schemes acknowledged but eliminated this concept for further investigation due to concept implementation complexity and corresponding high 
development cost relative to the above two concepts. However, revised expectations for lower security requirements for NTP engine reactor testing and the reduction in estimate of environmental hazard risks and impact concerns enabled expansion of test site options for consideration. Combined with an updated engine exhaust containment system concept that leverages existing NASA propulsion system test facility infrastructure in this system's design, this option trades well with the above 2 options. All analyses to date indicate this system will reliably and economically accomplish total containment of NTP engine exhaust. The facility fluid supply requirements are well within liquid rocket engine supply experience and in particular within existing SSC capability. SSC's systems analysis and modeling capabilities based on first-principles fluid physics and thermodynamics phenomena and routinely used to model, simulate, and predict the performance of SSC rocket propulsion test facilities show no significant technical issues with the total exhaust containment approach.

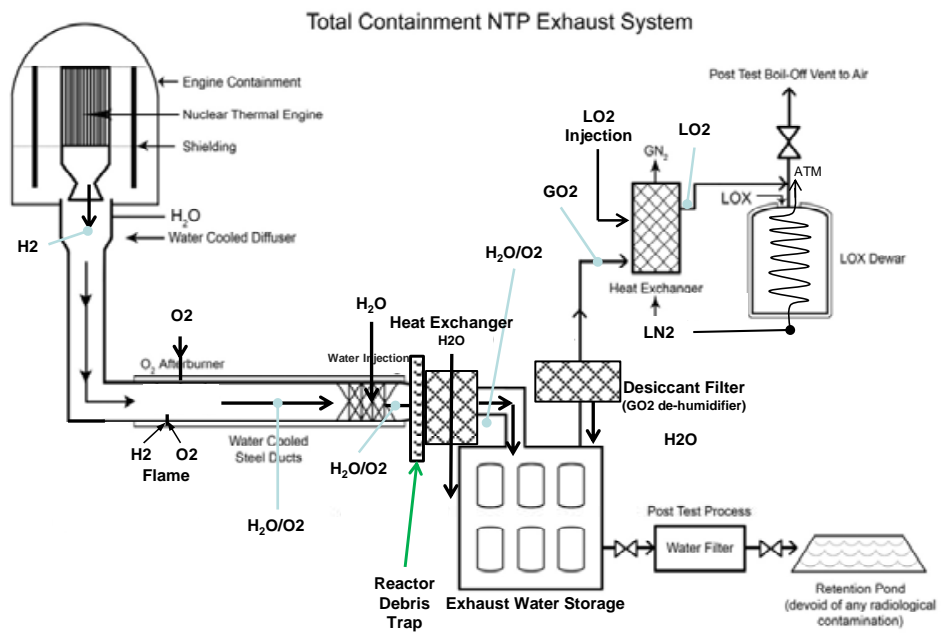

\section{NTP Engine Exhaust Total Containment Concept}

Specific facility designs, supporting engineering and operations performance analyses substantiating the technical merit of the NTP the above ground test options are provided in the following discussion. 